\title{
A warning for ecologists and conservation biologists using species checklists: How the European marine fauna 'lost' all of its 16 Discodoris species (Mollusca: Gastropoda)
}

\author{
Benoît Dayrat
}

Received: 30 April 2010 / Accepted: 18 June 2010 /Published online: 1 December 2010

(C) The Author(s) 2010. This article is published with open access at Springerlink.com

\begin{abstract}
The European marine fauna used to be considered to include 16 species of Discodoris sea slugs until a recent worldwide revision demonstrated that there is not a single Discodoris species in European waters. This exemplary case illustrates the fact that species checklists do not accurately represent biodiversity unless they are based on sound taxonomic work in which (1) the status of every available species name has been addressed, i.e. whether it is valid, synonymous, or of doubtful application, and (2) classification reflects phylogenetic relationships. It is argued that taxonomic revisions are critically needed, because the status of species names can only be addressed properly through revisions. It is discussed that fields which depend on taxonomic data, such as conservation biology and ecology, might be affected deeply if problematic species names (synonyms and nomina dubia) have not been recognized. Consequently, it is proposed that a taxon that has not been revised be red-flagged in checklists, so that non-taxonomists will know which species names should be applied with caution or not at all.
\end{abstract}

Keywords Biodiversity · Taxonomy · Nomenclature ·

Revision · Monograph

\section{Introduction}

The quality of the work done by all users of species names highly depends on taxonomists and their ability to keep lists

B. Dayrat $(\square)$

School of Natural Sciences, University of California,

5200 North Lake Road,

Merced, CA 95343, USA

e-mail: bdayrat@ucmerced.edu of species names up to date and accurate. Few ecologists appear to be aware of this and use species lists of widely varying quality to compare biological communities between localities. The same applies to conservation biologists determining whether an area deserves special protection. However, how lists of species names are built, improved, and maintained may not be sufficiently understood by nontaxonomists, because taxonomy is an independent field and non-taxonomists are often not familiar with its principles, practices, and debates. This should not be surprising, given that taxonomists in turn are not necessarily also experts in ecology or conservation biology. Here I document the problems with the uncritical use of species lists by documenting how an established species list for the allegedly 16 species of European sea slugs in Discodoris effectively shrank to nothing following a comprehensive taxonomic revision of the genus (Dayrat 2010a). I leave it up to the imagination of the reader to envision how such cases affect ecological inferences.

Taxonomists deal with names on a daily basis as much as they deal with organisms. In particular, in order to build reliable lists of species names, taxonomists must go through all the names from the literature and sort them. Indeed, not all species names available in the literature should be trusted and used. A newly created name for an animal species is regarded as 'available' in the sense of the international rules of nomenclature (the Code; ICZN 1999) when a number of conditions are met (concerning publication, use of Latin alphabet, etc.). However, not all available species names are equal. Only a subset of them is meaningful to users of species names: those that are valid. A valid name is the correct name that unambiguously refers to a species. All other names are either redundant (synonyms of valid names) or misleading (names of doubtful application, or nomina dubia). Problems arise 
when users apply names from species lists consisting of a mixture of synonyms, nomina dubia, and valid names that accumulate between taxonomic revisions or, in many cases, in the absence of any revision. Therefore, one of the key roles of taxonomists is to let non-taxonomists know the status of all available names, i.e. which of them can be used (as valid) and which should not (because they are synonyms and nomina dubia).

In most cases, users of species names have neither the time nor the necessary expertise to deal with the taxonomic literature and verify the status of the names they use. Instead, they mainly rely on checklists, the focus of which can be geographical (e.g., on the European marine fauna), taxonomical (e.g., sea-urchins of the world), or a combination of both (e.g., mollusks of Hawaii). All checklists, however, have in common that they reflect the taxonomic knowledge in the literature up to a given cut-off date. For taxa lacking a recent taxonomic revision, lists of species names may not be based on sound taxonomic knowledge, and downstream inferences may be erroneous. Indeed, taxonomic revisions are the only rigorous way to address the status of all available species names.

Here I explain what happened to the 16 species of Discodoris sea slugs listed in the European Register of Marine Species (Costello et al. 2001) after I revised the genus in a worldwide monograph (Dayrat 2010a). I also use Discodoris as a case study to (1) illustrate the three different categories of species names (valid names, synonyms, and nomina dubia); (2) argue that taxonomic revisions are critically needed as the only proper way to address the status of species names; (3) explain some of the regrettable consequences that can occur in fields such as conservation biology and ecology, if species names are used without knowledge of their status (valid, synonymous, or of doubtful application); and (4) propose that in species checklists, problematic species names should be flagged, so that non-taxonomists will know that those names should be used with caution or not at all.

\section{Discussion}

Valid names, synonyms, and nomina dubia

\section{Valid names}

Out of 16 Discodoris species names previously thought to denote species living in European waters, only three remain valid following revision of the genus (Dayrat 2010a; Table 1). Each of the three corresponding taxa is characterized by diagnostic features supporting its recognition as a separate species. For instance, the dorsal color of Peltodoris atromaculata is clearly distinctive, despite the fact that the size and number of dark areas vary among individuals (Fig. 1). However, these three species do not belong to Discodoris, of which they do not share the diagnostic autapomorphies. Indeed, Discodoris was found to be restricted to a small clade including only three species distributed in the tropical Indo-West Pacific, with no species in European waters. One of those three species is the type species of the genus (Discodoris boholiensis), hence the name of the clade (Fig. 2). The remaining two valid names formerly considered as representing European Discodoris belong to two other discodorid genera: Tayuva lilacina and Rostanga rosi (Fig. 2).

One of the common complaints heard from nontaxonomists is that taxonomists change names all the time. The three changes in generic combination discussed here are the result of a phylogenetic analysis, in which Peltodoris atromaculata, Tayuva lilacina, and Rostanga rosi were placed in clades other than Discodoris. Thus, these changes do not merely follow from some obscure nomenclatural rule but from the fact that taxonomic work takes place within the broader context of the Darwinian Tree of Life, in which names should reflect current phylogenetic knowledge. In the present case, Discodoris as traditionally defined was found to be polyphyletic, with former Discodoris species belonging to clades spread across Discodorididae (Figs. 1 and 2).

\section{Synonyms}

Three other Discodoris names from the checklist of Costello et al. (2001) have been identified as junior synonyms (Table 1). Based on morphological data (including a detailed analysis of intraspecific variation), it appears that Discodoris confusa, D. maculosa, and Tayuva lilacina all refer to the same biological unit. Discodoris confusa and D. maculosa are junior synonyms of Tayuva lilacina because the latter name was the first to become available (Principle of Priority, ICZN 1999).

Discodoris porri and D. indecora also refer to a single species, but the older of the two names, $D$. porri, has not been used as valid in the literature after 1899 , while $D$. indecora has been commonly used. Under such circumstances, Code Article 23.9 allows what is called a reversal of precedence where the younger name is regarded as valid because of its more common usage. So, contrary to what some non-taxonomists might think, disruption of common usage due to rediscovery of an older synonym can be averted even under the current rules of zoological nomenclature. The debate about priority versus usage has remained one of the most controversial in the history of nomenclature (Dayrat 2010b), and Article 23.9 has been criticized by some authors (e.g. Dubois 2010). 
Table 1 Comparison of species names before and after monographic revision of Discodoris sea slugs (Mollusca: Gastropoda: Opisthobranchia) thought to inhabit European waters

\begin{tabular}{|c|c|c|}
\hline $\begin{array}{l}\text { Discodoris species name } \\
\text { Before taxonomic revision }\end{array}$ & $\begin{array}{l}\text { Status } \\
\text { After taxonomic revision }\end{array}$ & $\begin{array}{l}\text { Species name } \\
\text { After taxonomic revision }\end{array}$ \\
\hline (Costello et al. 2001) & & (Dayrat 2010a) \\
\hline D. atromaculata (Bergh, 1880) & Valid & Peltodoris atromaculata Bergh, 1880 \\
\hline D. concinna (Alder \& Hancock, 1864) & Misidentification & Tayuva lilacina (Gould, 1852) \\
\hline D. confusa Ballesteros, Llera \& Ortea, 1985 & Synonym & Tayuva lilacina (Gould, 1852) \\
\hline D. edwardsi Vayssière, 1902 & Poorly known & "Doris" edwardsi (Vayssière, 1902) \\
\hline D. erubescens Bergh, 1884 & Unknown (species poorly known) & "Montereina” erubescens (Bergh, 1884) \\
\hline D. fragilis (Alder \& Hancock, 1864) & Misidentification & Tayuva lilacina (Gould, 1852) \\
\hline D. lilacina (Gould, 1852) & Valid & Tayuva lilacina (Gould, 1852) \\
\hline D. maculosa Bergh, 1884 & Synonym & Tayuva lilacina (Gould, 1852) \\
\hline D. millegrana (Alder \& Hancock, 1854) & Unknown (species poorly known) & Aporodoris millegrana (Alder \& Hancock, 1854) \\
\hline D. patriziae Perrone, 1991 & Nomen dubium & “Doris” patriziae (Perrone, 1991) \\
\hline D. porri (Vérany, 1846) & Synonym & Paradoris indecora (Bergh, 1881) \\
\hline D. punctifera (Abraham, 1877) & Unknown (species poorly known) & "Montereina" punctifera (Abraham, 1877) \\
\hline D. rosi Ortea, 1979 & Valid & Rostanga rosi (Ortea, 1979) \\
\hline D. rubens Vayssière, 1919 & Nomen dubium & Geitodoris rubens (Vayssière, 1919) \\
\hline D. sordii (Perrone, 1990) & Nomen dubium & “Montereina” sordii (Perrone, 1990) \\
\hline D. stellifera (Vayssière, 1903) & Unknown (species poorly known) & “Doris" stellifera (Vayssière, 1903) \\
\hline
\end{tabular}

Generic names in quotation marks refer to taxa that are not monophyletic

\section{Nomina dubia}

Three Discodoris names from the checklist correspond to what the Code identifies as names of doubtful application, or nomina dubia (Table 1). While the concepts of valid and synonymous names are usually understood by nontaxonomists, the same does not apply to nomina dubia. Generally, a species name can be regarded as a nomen dubium when the available information does not allow one to identify which species the name refers to. Frequently this is the case because the type material is lost, destroyed or not publicly accessible; more exceptionally, the type material is available but not informative. Also, the original description of a taxon labelled with a nomen dubium usually is poorly informative, e.g. too short or vague, or lacking key characters or illustrations. For example, Discodoris patriziae is a nomen dubium, because the holotype is not publicly available, no paratypes were deposited in any public institution, and the original description is poorly informative. Thus, Discodoris patriziae, like all nomina dubia, exists in the literature but cannot be linked reliably to any actual biological species. Altogether, nomina dubia are rare in some taxa, but common in others.

\section{Names that refer to poorly known species}

Five Discodoris names refer to poorly known species (Table 1), which is not a status category recognized by the ICZN. Poorly known species are, in general, only known from the original material and description. The corresponding names are not nomina dubia, at least not yet, because some available information could potentially help future identification; for instance, the type material might be informative, or the original description includes an unusual feature that could be diagnostic. However, due to lack of material the species remains poorly known, and it is unclear whether the species name is valid or not. Additional material from the type locality [where the name-bearing type(s) was(were) collected] would likely help determine the status of the species name.

Discodoris erubescens, for instance, refers to a poorly known species. It has been cited in several publications as a Mediterranean Discodoris, but is only known from the holotype, originally collected from Trieste, Adriatic Sea, and which is likely lost. However, the original description mentioned the presence of 12 dorsal, bipinnate gills, which is fairly unusual in Discodorididae (there are about six 4pinnate gills in most species). So, newly-collected samples from the type locality might help address the status of $D$. erubescens, which could be valid, a synonym (e.g., a Baptodoris species with similar gills was described from the Canaries), or a nomen dubium if not even intensive collecting produces any individuals matching the original description. At this time, $D$. erubescens remains poorly known, at least compared to a species like Peltodoris atromaculata for which dozens of records have been published. 

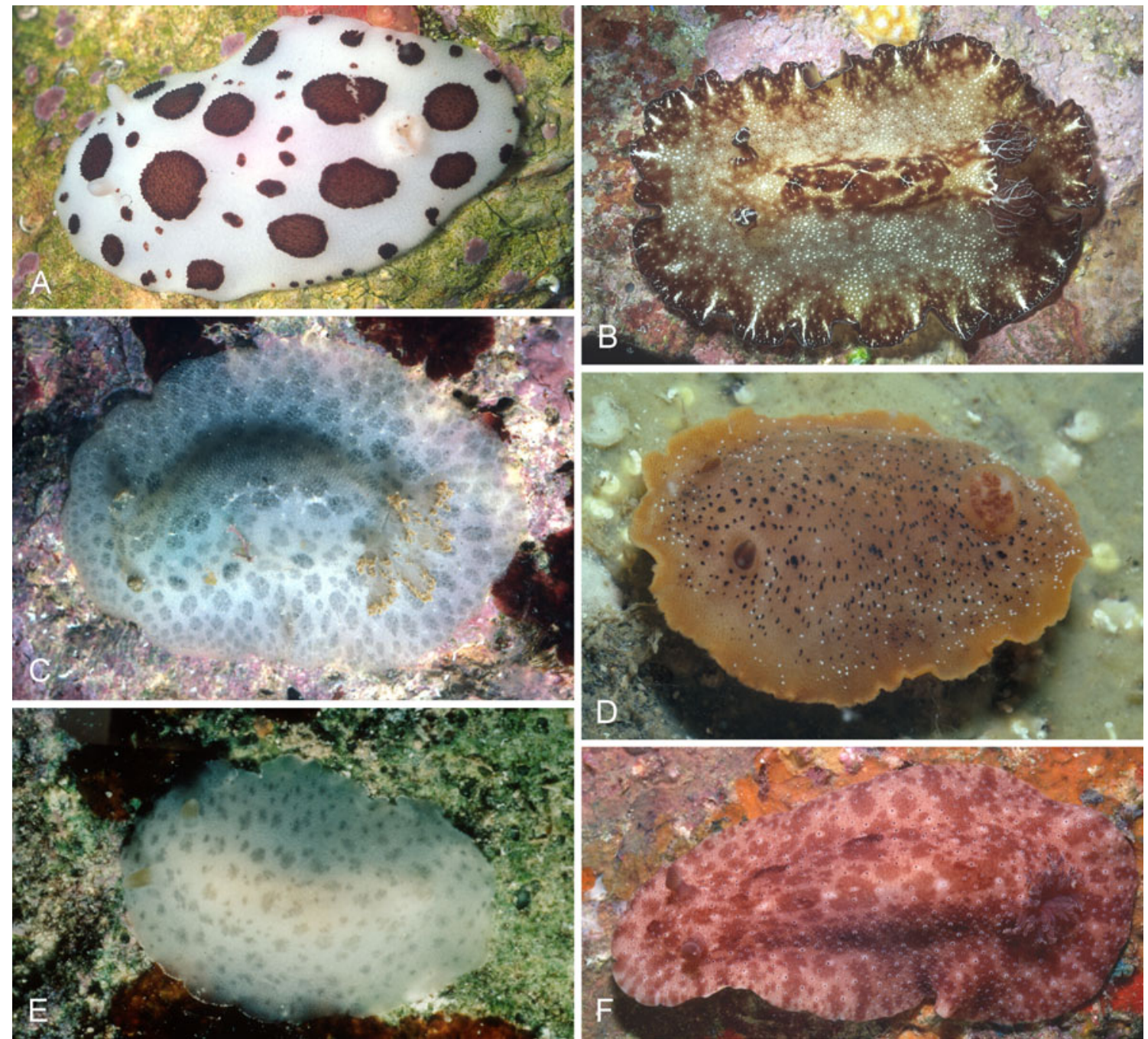

Fig. 1 Live discodorid sea slugs, dorsal views. a Peltodoris atromaculata Bergh, 1880. b Discodoris boholiensis Bergh, 1877. c Tayuva lilacina (Gould 1852). d "Montereina" aurila (Marcus and

Marcus 1967). e "Montereina" coerulescens (Bergh, 1888). f "Montereina" rubra (Bergh 1905). Photos by T. M. Gosliner. For additional information about the vouchers, see Dayrat (2010a)

\section{Misidentifications}

Finally, two Discodoris names were cases of misidentification (Table 1), i.e. a species name was given to specimens that are not members of that species. For instance, specimens identified in the past as Discodoris fragilis actually belong to Tayuva lilacina, whereas Sebadoris fragilis is restricted to the tropical Indo-West Pacific and does not occur in European waters.

\section{A praise of taxonomic revisions}

Revisions differ from regular, shorter taxonomic contributions because they are in essence monographic: ideally, all type specimens as well as other museum collections are examined; the status of every name is addressed; etc. Revisions often take a long time to be completed, reviewed,

and published, but taxonomic work should ideally not be split in shorter contributions just because they are less demanding (although short follow-up work after having done revisions makes sense). Regardless, revisions remain the highest standard for taxonomic work because they are comprehensive. Generally speaking, revisions are the only rigorous way to clear the ground for future studies in a particular taxon (Meier and Dikow 2004). For instance, it is much more difficult to recognize truly new species and create new names that will not turn out to be synonyms without first addressing the status of all existing names.

Monographic revisions are also important because they reveal which data are still missing. For instance, new collections are needed for the five poorly known species (Table 1), and most importantly from their respective type localities: Moroccan coast, off Cap Ghir, $2100 \mathrm{~m}$ depth ("D." edwardsi); Adriatic Sea, Trieste ("M." erubescens); 


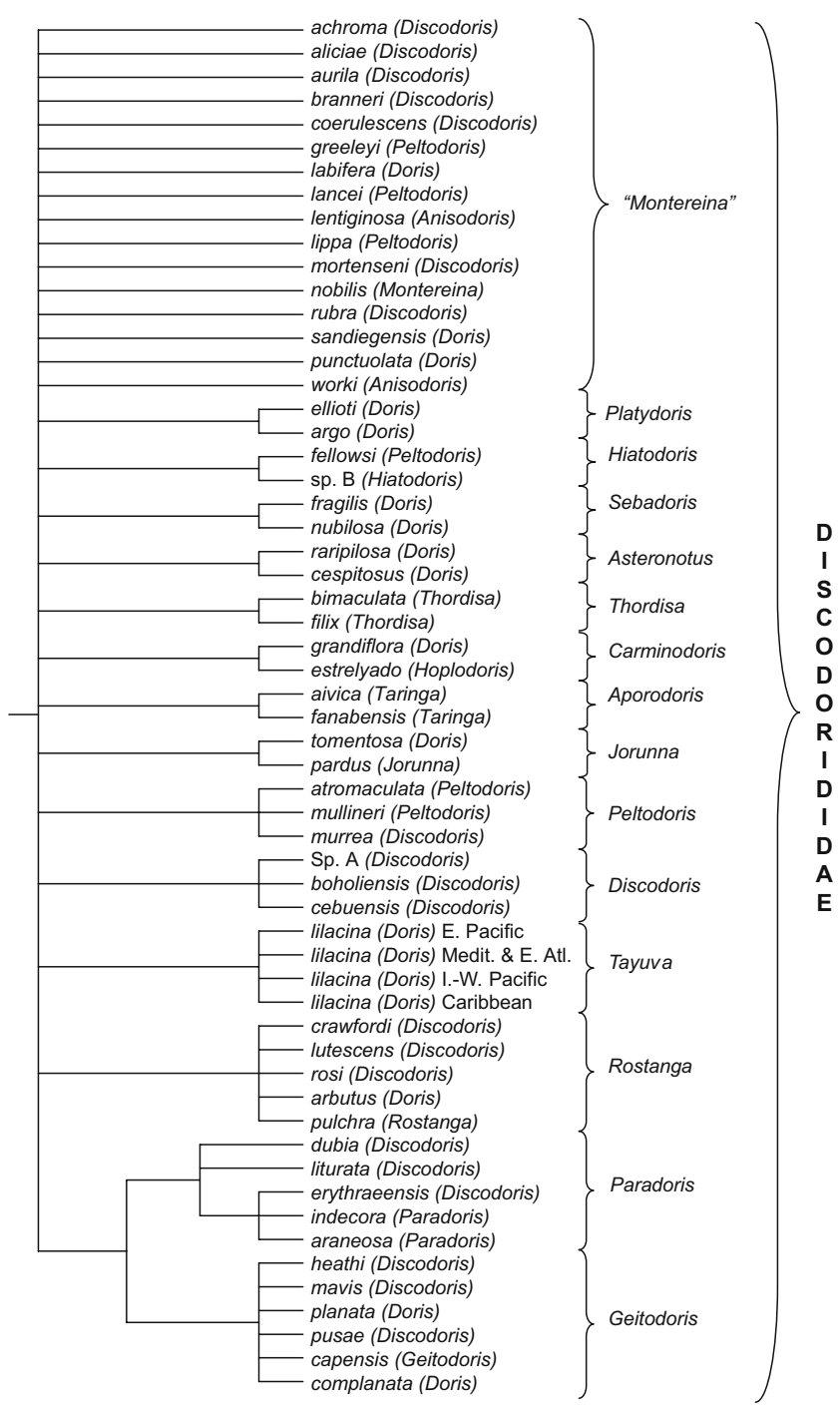

Fig. 2 Phylogenetic tree representing relationships within Discodorididae. The latter contains about 400 species and 40 genera, only some of which are mentioned here, with special emphasis on the genera that contain species originally described in Discodoris. Tree terminal taxa are labeled with the specific epithet followed by the generic name of the original combination in parenthesis. The current generic names are given on the right side of the braces indicating the (few) species per genus mentioned. Assignment of a generic name to a clade is based on a type species that belongs to that clade (e.g., Discodoris boholiensis is the type species of Discodoris). All genera correspond to clades, with the exception of "Montereina", a metaphyletic group at the base of Discodorididae for which no autapomorphic, diagnostic features could be found. For additional information on phylogenetic analyses, authorship of species names, etc., see Dayrat (2010a)

English Channel, UK, Torquay (A. millegrana); Canary Islands, Tenerife ("M." punctifera); Italy, Gulf of Naples, and France, Gulf of Marseille, Sète, and Etang de Thau ("D." stellifera). Although it is unclear whether these five species names will remain valid or represent synonyms, there is hope that their status will be clarified once new specimens become available. Those five poorly-known species help illustrate a situation which, contrary to what one might think, is not uncommon: new collections are still needed from European waters although the latter have been one of the most explored regions in the world.

One could argue that Tayuva lilacina, the name of which is cited as valid here, also is a poorly known species. Indeed, T. lilacina refers to a worldwide species complex (Mediterranean and eastern Atlantic, Panamic eastern Pacific, tropical Indo-West Pacific, Caribbean). Due to high intraspecific character variation, morphology does not help distinguish units within the Tayuva lilacina species complex, for which new kinds of data (e.g., DNA sequences) are needed in the context of phylogeographic and population studies. It is conceivable that, when new data become available, Tayuva lilacina will have to be split in several species: for example, if the Tayuva from European waters differs from the others, then its valid species name would be $T$. maculosa (the oldest name available in the region). Here again, a taxonomic revision helps determine what new collections and new kinds of data are needed. Given that time and resources are limited, one may want to acquire DNA sequences first for targeted species of which the delineation is puzzling (Petersen et al. 2007). A taxonomic revision is an ideal way to identify those priority species: a revision of Discodoris clearly identified the Tayuva lilacina species complex as a priority for the use of DNA sequences to identify potential cryptic species.

As for the nomina dubia, they should just be ignored in checklists. Recognizing nomina dubia requires an expertise that is only achieved during revisionary work. Therefore, problems caused by nomina dubia can only be solved by revisionary studies. Note that nomina dubia can be quite common, in which case a large number of species names in the literature is difficult to interpret until a revision has been completed. During the revision of Discodoris, for example, 119 species names were scrutinized and the number of nomina dubia rose from 2 to 27 (Dayrat 2010a).

Revisions, as for any other kind of taxonomic work, remain subjective. Thus, results made available through revisions cannot be regarded as a truth permanently carved in stone. In fact, taxonomists may disagree about the status of some species names. Despite this, revisions still constitute the highest standard for taxonomy for all the reasons given above.

Species names as potential sources of confusion in biodiversity studies

The revision of Discodoris illustrates that available species names are not all equal. Strictly speaking, only valid species names should be included in checklists because only valid names provide us with an accurate representation of species diversity. In contrast, unrecognized synonyms and nomina dubia introduce a great deal of inaccuracy in 
species checklists and diversity estimates and, thus, ultimately in all studies that use such estimates and species lists. So, knowing the status of every available species name is critically important. In recent years a few initiatives (e.g. GBIF, Species 2000, World Register of Marine Species) have flourished that collect species names and make them available online. Although highly desirable and useful, those initiatives tend not to indicate the status of the names collected and whether that status has ever been addressed through a revision, which prevents users of those lists from realizing that the status of a large number of names is uncertain.

After the revision of Discodoris, only three out of 16 Discodoris species names previously associated with European waters remained valid. Naturally, this deeply affects biodiversity estimates for sea slugs in European waters. Actually, to the unenlightened it might seem that the European fauna lost 13 species, when instead most of these are paper losses and at the same time the continent gained several genera. The European Register of Marine Species (Costello et al. 2001) did not include the genera Peltodoris, Tayuva, and "Montereina" (it did not include Aporodoris either, but the latter is the valid name for Taringa, listed in the Register). The species diversity might be lower than what we had thought, but we know better which parts of the Tree of Life are represented in European waters. This is critical, e.g., to scientists comparing the diversity of European waters to that of other biogeographic provinces, and numbers of genera or of species per genus among different regions. Generally speaking, because phylogenetic information is used in community ecology as well as in conservation biology, classifications that do not reflect phylogenetic relationships lead to erroneous inferences. Therefore, checklists must be accurate not only concerning species names, but also for the supraspecific classification, which should reflect phylogenetic relationships.

If synonyms are not recognized, they become mixed with valid names and, as redundant names, artificially inflate biodiversity estimates. Before the revision of Discodoris, the biological unit now referred to as Tayuva lilacina was represented by five different species names. The fact that synonyms exist in the literature is not an issue. The real problem is that some synonyms are mixed with valid names because they have not been recognized. Synonyms should probably continue to be cited in checklists, because it happens that taxonomists disagree over the status of some names. However, potential synonyms have to be stamped as such so that one species is not counted more than once in biodiversity estimates. Nomina dubia are much more problematic. In contrast to synonyms, they remain ambiguous even after they are recognized because they cannot be resolved. They should either be removed from checklists, or stamped as nomina dubia so that ecologists, conservation biologists, and other users of species names know that they should not consider them.

Synonyms and nomina dubia introduce potential inaccuracy to our interpretations of species distribution and abundance, which are so critical for conservation. Naturally, a species with a localized distribution and few published records will more likely attract conservation efforts than a widespread, abundant species. For instance, Discodoris sordii is only known from the holotype and one paratype, both collected from Porto Cesareo on the Mediterranean Sea. From this, D. sordii could be regarded as a rare, endemic species. The reality is quite different, at least from the author's point of view: Discodoris sordii is a nomen dubium that should be ignored.

Finally, the status of species names is specifically critical to a good understanding of endemism. Rates of endemism are potentially dramatically inflated by species names referring to 'endemic' species which, in reality, are just nomina dubia or synonyms. For instance, the European Register of Marine Species (Costello et al. 2001) mentioned five species of Paradoris, three of them as restricted to the Canary Islands. However, a worldwide revision of Paradoris (Dayrat 2006) has led to the conclusion that there is only one species of Paradoris in European waters, with Paradoris indecora as its valid name, Discodoris porri as one of the five junior synonyms. In any case, the Canary Islands do not seem to be a center of endemism for Paradoris ( $\sim 10$ valid species names, worldwide).

\section{Red flags for users of species names}

One could argue that Discodoris might be an exception and that not all the European fauna is in comparable taxonomic chaos. Certainly, some taxa are better known than Discodoris was prior to its revision. However, any list of names for a taxon that has not been revised is potentially problematic. Unfortunately, a large portion of the European fauna has never been revised, because the number of taxonomists has been in decline for at least 30 years, and the number of taxa requiring work is enormous and growing. Naturally, the situation is even worse for faunas that have received much less attention (e.g., those in the tropics).

Regardless, it seems critical to find a way to indicate to non-taxonomists using species names and taxonomic data, (1) whether the status of a given species names is established and reliable, and (2) which source(s) that information is based on. As argued above, the most rigorous way to address the status of species names is a monographic revision. Simply indicating a status is not satisfactory, because if a taxon has never been revised, available species names are often listed as valid by default. That situation is well illustrated by Discodoris, in which all 16 supposedly European species names were 
regarded as valid prior to revision, simply because their status had never been addressed properly. If the status of a species name has never been addressed, then it should not be regarded as 'valid' by default, but as unknown instead. Thus, it would be greatly helpful if checklists cited actual taxonomic revisions from which the status of species names was obtained. That would help users to go back to original sources, help credit the hard work of taxonomists, and emphasize that, in the absence of a revision, the status of species names should be regarded as unknown.

Although, generally speaking, the existence of a revision of a particular taxon is an indication that the species names within that taxon have been thoroughly evaluated at least once, the citation of a revision does not necessarily solve all problems. In groups in which a great deal of active collecting continues and additional species are described frequently, the questions are how recent the latest revision is, and whether it has accounted for all specimens and species names accumulated up to the present. There certainly are problematic genera which were revised 10 or 20 years ago and for which a new revision is needed, because thousands of new specimens have been collected and many new species described since then. On the other hand, there certainly also are taxa for which a high-quality revision was completed 50 years ago, in which valid names have remained so because few specimens and no new species have been added. Therefore, when a revision is available, both compilers and users of checklists should consider its date of publication as well as the volume of additions since the revision to get a sense of whether the revision might be outdated.

Given that, in reality, many users of species names might have neither the time nor the expertise to explore the taxonomic literature (especially monographic revisions), it could be helpful if checklists indicated whether any included species names are potentially problematic. It is suggested here that a red flag be used next to a taxon name at genus or higher level, to indicate that species names in that taxon are problematic for any of the following reasons: (1) the taxon has never been revised; (2) a revision exists but is possibly outdated, because new species names have accumulated since; (3) several revisions are available and disagree with each other. To be more explicit, checklists could even specify that the status of species names is uncertain or in need of study when a revision is lacking.

It is necessary to emphasize that taxonomists who have not worked on a particular taxon cannot judge whether the taxonomy of that taxon is well or poorly known. Indeed, the concept of the taxonomic 'expert' is actually much narrower than most non-taxonomists might think. For instance, although I have been publishing papers on the systematics and evolution of sea-slugs, or opisthobranchs, for the past ten years, as far as species-level taxonomy goes I am only an expert on the taxa that I have revised (Discodoris, Paradoris, Peltodoris, etc.). As a result, I cannot evaluate whether the list of 33 species names in the sea-slug genus Doto in the European Register of Marine Species (Costello et al. 2001) is reliable or not, because that would require a monographic revision of Doto as a whole. However, the genus Doto ( $\sim 100$ available species names, worldwide) has never been revised; also, no phylogenetic analysis is available that would support its circumscription. Thus, although I am not an expert on the taxonomy of Doto, I can reasonably say that Doto in a checklist would probably deserve a red flag, because (1) some species might belong to another genus; (2) there might be species not listed in Doto that actually belong to it; (3) some of the 33 species names listed for the European waters might be synonyms or nomina dubia.

If one were to start adding red flags next to the names of potentially problematic taxa, some pages in checklists would become quite red, even in cases of regions that have been studied abundantly, such as North America and Europe. This would help make non-taxonomists understand that the need for taxonomy and taxonomists is real and urgent. The fact that checklists like the European Register of Marine Species would include many red flags does not imply that those checklists could not be valuable resources. Checklists are very useful for both taxonomists and non-taxonomists, and their authors cannot be held responsible for the shortcomings of data in the taxonomic literature. However, because checklists are an important means of communication between taxonomists and non-taxonomists, it is essential that they become more informative and explicit about the quality of the taxonomic work they are based on. Thus, it is highly desirable for checklists to indicate for each included genus- or family-level taxon whether or not it has been revised, so that users of may estimate whether species names in that taxon are trustworthy or potentially problematic, and thus may avoid downstream problems in their own work.

Regardless of whether or not red flags will be put in place in future checklists, all users whose work depends on the quality of taxon names should always examine the quality control measures taken by the makers of the checklist. Not everyone has the time to become familiar with the literature on a particular taxon, but a quick check whether any taxonomic revision is cited as a source for a checklist can provide much insight for little effort. Hopefully, readers of the present contribution are convinced by now that, if no revision is cited, then a list of species names is potentially problematic. 
More generally, raising red flags for all taxa in need of study would also be a way to inform (again) biologists and the society at large about how poorly we know biodiversity and how critical it is to support taxonomy, the science in charge of putting some order into the study of that diversity. In particular, it might be useful to attracting the attention of ecologists, who in general are only mildly supportive of taxonomy, to the fact that some of their work relying on taxonomic resources might contain unsuspected errors that mathematical models are unable to detect and correct. And, to avoid any misunderstanding: the problem is not that taxonomists do a poor job, but that fewer and fewer of us are able to spend time on what would need to be done, i.e. on revising taxa through monographic work.

Acknowledgements I am grateful to Rudolf Meier for an engaging discussion at the National University of Singapore, which ultimately led to the present paper. Rudolf Meier, Olaf Bininda-Emonds, Martin Spies, and two anonymous reviewers provided constructive comments that greatly improved the manuscript. The present work was supported by a grant from the US National Science Foundation (DEB-0933276, to BD).

Open Access This article is distributed under the terms of the Creative Commons Attribution Noncommercial License which permits any noncommercial use, distribution, and reproduction in any medium, provided the original author(s) and source are credited.

\section{References}

Costello, M. J., Emblow, C., \& White, R. (Eds.) (2001). European register of marine species: A check-list of the marine species in Europe and a bibliography of guides to their identification. Paris, France: MNHN, Collection Patrimoines Naturels.

Dayrat, B. (2006). A taxonomic revision of Paradoris sea slugs (Mollusca: Gastropoda: Nudibranchia: Doridina). Zool J Linn Soc, 147, 125-238.

Dayrat B (2010a) A monographic revision of basal discodorid sea slugs (Mollusca: Gastropoda: Nudibranchia: Doridina). Proceedings of the California Academy of Sciences, Series 4, 61(Suppl. I), 1-403. [PDF freely available at: http://research.calacademy. org/scipubs/pubs/1831]

Dayrat, B. (2010b). Celebrating 250 dynamic years of nomenclatural debates. In A. Polaszek (Ed.), Systema naturae 250, The Linnean Ark (pp. 185-239). Boca Raton: CRC Press.

Dubois, A. (2010). Zoological nomenclature in the century of extinctions: priority vs. 'usage'. Org Divers Evol, 10, 259-274.

ICZN = International Commission on Zoological Nomenclature. (1999). International code of zoological nomenclature (4th ed.). London: International Trust for Zoological Nomenclature.

Meier, R., \& Dikow, T. (2004). Significance of specimen databases for estimating and mapping the global diversity of invertebrates and repatriating reliable specimen data. Conserv Biol, 18, 478-488.

Petersen, F. T., Damgaard, J., \& Meier, R. (2007). DNA taxonomy: How many sequences are needed for solving a taxonomic problem? The case of two parapatric species of louse flies (Diptera, Hippoboscidae: Ornithomya Latreille, 1802). Arthr Syst Phyl, 65, 119-125. 